\title{
AVALIAÇÃO PÓS-OCUPAÇÃO NO ENSINO DE PROJETO DE ARQUITETURA: UMA EXPERIÊNCIA DIDÁTICO-PEDAGÓGICA NA DISCIPLINA “ATELIER DE PROJETO INTEGRADO V"
}

\author{
POST-OCCUPANCY EVALUATION IN ARCHITECTURAL \\ DESIGN TEACHING: A DIDACTIC-PEDAGOGICAL \\ EXPERIENCE IN ATELIER DE PROJETO INTEGRADO V \\ COURSE
}

\author{
Simone Barbosa Villa', Rita de Cássia Pereira Saramago', Débora Cristina \\ Araújo ${ }^{1}$
}

RESUMO: A relevância da Avaliação Pós-Ocupação (APO) para obtenção da qualidade do projeto de arquitetura tem sido comprovada por diversas pesquisas na área da construção civil. Aspectos relacionados à gestão do processo de projeto, em que a APO se insere, e seu papel no atendimento à qualidade dos espaços construídos, notadamente nas habitações, também já foram amplamente discutidos. Assim evidencia-se a profunda relação existente entre a aferição do comportamento humano no espaço doméstico e a qualidade habitacional como forma de se elevar os índices de satisfação dos usuários e de promover a melhoria do desempenho dos projetos, especialmente para novas propostas. É nesse sentido que se encontra a contribuição da APO para o ensino de projeto. Este artigo discute, portanto, a validade do emprego de instrumentos de APO como metodologia diferenciada de ensino que pode se constituir como elemento norteador do processo projetual em disciplinas de projeto, ou ateliê, na graduação em Arquitetura e Urbanismo. Para tanto, apresenta a experiência didático-pedagógica que vem sendo desenvolvida na disciplina Atelier de Projeto Integrado V, cujo tema é Habitação de Interesse Social (HIS), ministrada a alunos do quinto período do curso de Arquitetura e Urbanismo da Universidade Federal de Uberlândia. Essa disciplina busca desenvolver uma visão crítica sobre a atual produção de HIS no Brasil, através de aulas expositivas, da apresentação de obras referenciais e da aproximação dos alunos com a realidade analisada mediante a aplicação de algumas técnicas de avaliação em estudos de caso. Os resultados dessa experiência têm demonstrado que a APO pode influenciar o processo de concepção projetual, especialmente no caso dos estudantes, profissionais em formação, instigando-os no desenvolvimento de soluções que visem reduzir e/ou sanar as problemáticas identificadas.

PALAVRAS-CHAVE: Avaliação Pós-Ocupação; Ensino de Projeto; Habitação de Interesse Social.

ABSTRACT: The relevance of Post-Occupancy Evaluation (POE) in the achievement of more qualified architectural design has been proven by several researches in the area. Aspects related to design management process, in which POE is inserted, and yet their role in built spaces quality, especially in housing, have been widely discussed as well. Therefore a deep relationship between human behavior assessment in domestic space and housing quality as a way to increase resident's satisfaction level and improve design performance, especially for new proposals, is evidenced. In this sense, POE can contribute to Architectural Design teaching. Thus, this article discusses the importance of using POE tools as a different teaching methodology, that can be used as guiding element for design process in Design Studio disciplines, in Architecture and Urbanism bachelor degrees. For that, it presents the pedagogical experience developed in Atelier de Projeto Integrado V, which theme of investigation is social housing, taught

\section{How to cite this article:}

VILLA, S. B.; SARAMAGO, R. C. P.; ARAÚJO, D. C. Avaliação pós-ocupação no ensino de projeto de arquitetura: uma experiência didático-pedagógica na disciplina "Atelier de Projeto Integrado V". Gestão e Tecnologia de Projetos, São Carlos, v. 13, n. 1, p. 7-20, 2018. http://dx.doi.org/10.11606/gtp.v13i1.124496

Fonte de financiamento: Conselho Nacional de Desenvolvimento Científico e Tecnológico (CNPq) Fundação de Amparo à Pesquisa de Minas Gerais (Fapemig), Pró-reitoria de Graduação da Universidade Federal de Uberlândia (Prograd-UFU)

Conflito de interesse: Declaram não haver

Submetido em: 16/12/2016 Aceito em: 08/10/2017 
to students of the fifth semester in the Faculty of Architecture and Urbanism of the Federal University of Uberlândia (Brazil). This discipline seeks to develop a critical view on current Brazilian social housing production through lectures, presentation of key works and approximation of students with the reality by the application of some POE tools in case studies (field works). The results from this experience have demonstrated that POE can influence the design conception process, especially in students, trainee professionals, instigating them to develop solutions that aim to reduce or solve the identified problems.

KEYWORDS: Post-Occupancy Evaluation; Architectural Design Teaching; Social Housing.

\section{INTRODUÇÃO}

A importância da aplicação de instrumentos de Avaliação Pós-Ocupação (APO), visando qualidade do projeto de arquitetura, tem sido discutida por diferentes estudos na área da construção civil (VOORDT; WEGEN, 2013; VILLA; ORNSTEIN, 2013). Também a gestão do processo de projeto, em que a APO se insere, e seu papel no atendimento à qualidade dos espaços construídos, especialmente das habitações, já foram comprovados pela literatura (KOWALTOWSKI et al., 2011). Portanto, nessas pesquisas nota-se que a aferição do comportamento humano no espaço doméstico influencia a qualidade habitacional, à medida que tem o potencial de elevar índices de satisfação dos usuários (moradores) e de incentivar soluções projetuais de maior desempenho, apontando caminhos para a melhoria de propostas futuras. É nesse sentido que se encontra a contribuição da APO para o ensino de projeto.

Nesse contexto, este artigo discute a relevância do emprego de APO como metodologia diferenciada de ensino que pode se constituir como elemento norteador do processo projetual em disciplinas de projeto ou ateliê na graduação em Arquitetura e Urbanismo. Com esse intuito, apresenta a experiência didático-pedagógica desenvolvida desde 2009 na disciplina "Atelier de Projeto Integrado V" (API V), cujo tema é Habitação de Interesse Social (HIS), ministrada a alunos do quinto período do curso de Arquitetura e Urbanismo da Universidade Federal de Uberlândia. Tal disciplina objetiva fomentar a crítica sobre a produção atual de HIS, enfocando a importância da APO como processo analítico crítico de ambientes habitacionais de interesse social. Para isso são utilizadas aulas expositivas com debates sobre os conteúdos apresentados, da indicação de obras referenciais e da aproximação dos alunos com a realidade analisada por meio da aplicação de alguns instrumentos de avaliação em estudos de caso.

Para tanto, este artigo foi estruturado da seguinte forma: inicialmente são tecidas considerações sobre a relação entre a APO e o ensino de projeto; em seguida, é discutida a experiência da APO na disciplina API V, indicando seus objetivos e características; e, por fim, apresentamos a aplicação da metodologia de avaliação desenvolvida para a disciplina em um dos estudos de caso, os resultados dessa APO e seus impactos no desenvolvimento das soluções de projeto.

\section{AVALIAÇÃO PÓS-OCUPAÇÃO E O ENSINO DE PROJETO}

A Avaliação Pós-Ocupação pode ser definida como um conjunto de métodos e técnicas aplicado a edificações em uso, passado algum tempo de sua entrega definitiva, com o objetivo tanto de medir o desempenho físico das mesmas, mediante a análise de especialistas, quanto de aferir os níveis de satisfação dos usuários (EVANS; MCCOY, 1998; ORNSTEIN; BRUNA; ROMÉRO, 1995; MALLORY-HILL; PREISER; WATSON, 2012). Importa, assim, 
relacionar as duas formas de levantamento de dados (perspectiva dos especialistas e opinião dos usuários) entre si para construir um repertório mais amplo sobre as edificações em estudo.

Destaca-se, na aplicação dos instrumentos de APO, justamente a participação ativa dos usuários, os quais, ao apontarem os aspectos positivos e negativos dos espaços, permitem aos pesquisadores conhecer melhor as decisões de projeto e de obra que geraram os acertos e erros vivenciados. Torna-se possível, portanto, indicar diretrizes para a elaboração de programas de manutenção, uso e operação dos próprios estudos de caso; subsidiar a discussão e implementação de normas para um setor específico; bem como apontar soluções para novas intervenções em projetos semelhantes (ORNSTEIN, 2002; ELALI; VELOSO, 2006).

No Brasil, os resultados desse tipo de pesquisa têm sido usados, sobretudo, para embasar o desenvolvimento de propostas arquitetônicas diferenciadas (ORNSTEIN, 2002). Salienta-se, assim, o importante papel que os bancos de dados alimentados por avaliações pós-ocupacionais podem desempenhar enquanto apoio no aprimoramento da qualidade projetual de futuras edificações. É nesse sentido que se encontra a contribuição da APO para o ensino de projeto. Afinal, conforme Elali e Veloso (2006), a análise de precedentes também influencia a construção do repertório formal e funcional de futuros arquitetos e, por isso, as avaliações pós-ocupacionais têm se consolidado enquanto importantes modos de investigação sobre o ambiente construído.

Esse tipo de avaliação se diferencia das usuais visitas técnicas a edifícios e conjuntos edificados, ou mesmo das frequentes e tradicionais análises de estudos de caso, geralmente realizadas em algumas disciplinas de projeto, na medida em que possibilita o conhecimento mais aprofundado das soluções adotadas e de suas consequências para os usuários - em termos técnico-construtivos, funcionais, comportamentais e ambientais. Ademais, a APO constitui disciplina consolidada, com extensa literatura nacional e internacional específica - a exemplo de clássicos como Sommer e Sommer (1997) e Preiser, Rabinowitz e White (1988), além de estudos mais recentes como os apresentados na obra organizada por Villa e Ornstein (2013) disponibilizando dados estatísticos e científicos aos pesquisadores, ou seja, garantindo-se a construção de informações e conhecimentos válidos do ponto de vista metodológico e científico.

Dado o exposto, este trabalho defende a hipótese de que o emprego de instrumentos de APO pode fundamentar, de maneira mais precisa, o raciocínio projetual em disciplinas de graduação em Arquitetura e Urbanismo, apresentando-se, para ilustrar tal percepção, a experiência que vem sendo desenvolvida na disciplina API V.

\section{Por que empregar APO na disciplina "Atelier de Projeto Integrado V"?}

Segundo Elali (2010, p. 9): "Em todos os contextos e situações vivenciados no cotidiano as pessoas fazem avaliações: da escolha de um alimento à seleção de amigos, da atividade escolar à preferência por um filme”. Com relação ao ambiente construído, a autora afirma que essa condição também se evidencia à medida que as pessoas analisam continuamente o local no qual se encontram, habitam ou trabalham, tecendo considerações tanto em termos do conjunto quanto no que diz respeito a características específicas dos ambientes internos às edificações.

No entanto, o aluno do curso de Arquitetura e Urbanismo acaba por ultrapassar essa dimensão natural para uma dimensão mais técnica e, portanto, mais aprofundada de análise. Isso porque, a partir do momento em que o discente inicia um processo intenso de imersão no conhecimento técnico da área, seus processos de avaliações naturais são, de certa forma, alterados. Assim, dimensões técnicas mais específicas se agregam às 
percepções cognitivas naturais do aluno. Nessa dimensão mais técnica da construção do conhecimento, se faz relevante o emprego de processos de avalição científicos e precisos que possam melhor fundamentar a prática projetual dos estudantes. Reforça-se também o argumento de que a atividade criativa de arquitetos e designers se fundamenta no conhecimento e na adaptação de precedentes - portanto, não pode ser entendida enquanto uma "tábula rasa”, ou mesmo como fruto da simples consideração de critérios estruturais e programáticos (MAHFUZ, 1995).

Nesse sentido, a inserção da APO simplificada ${ }^{1}$ na disciplina API V do curso de Arquitetura e Urbanismo pretende implementar as seguintes questões: (1) propiciar ao aluno o contato direto com o objeto de estudo e seus problemas reais a serem resolvidos; (2) fornecer ao discente o contato com experiências de vida diferentes das que habitualmente possui, auxiliando a expansão de seu repertório; (3) oferecer procedimentos metodológicos precisos e adequados de avaliação (instrumentos e técnicas) para obtenção de informações igualmente mais precisas, ampliando a cientificidade das ações no processo de projeto; e (4) apresentar ao graduando procedimentos metodológicos planejados de avaliação para o desenvolvimento do processo de projeto.

Conforme exposto, a disciplina API V tem como objetivo principal desenvolver projetos integrados de arquitetura, urbanismo e paisagem com ênfase sobre a questão da Habitação de Interesse Social (HIS). Essa disciplina pretende discutir sobre modelos de HIS e de sua implantação no Brasil, preparando os alunos a um exercício projetual crítico, calcado nas reais necessidades da sociedade brasileira. Pretende também discutir, na escala bairro, questões relativas à produção de espaços de habitação coletiva de qualidade, inserindo ainda aspectos tecnológicos ao projeto arquitetônico em nível de anteprojeto, além de propor a utilização da APO como condicionante projetual.

Os trabalhos de avaliação e análise do estudo de caso ocupam a primeira parte da disciplina, sendo que, desde 2009, exercícios semelhantes de APO simplificada vêm sendo aplicados sistematicamente na disciplina em questão - algumas experiências iniciais já foram relatadas (VILLA; CAMPOS; BRAGA, 2010; VILLA et al., 2013; SARAMAGO et al., 2015). Esta comunicação apresenta, assim, estudos desenvolvidos ao longo do primeiro semestre de 2015, com aplicação de uma metodologia de avaliação no Condomínio Embaúba do empreendimento Cidade Verde, construído na periferia da cidade de Uberlândia (MG) como parte do programa "Minha Casa Minha Vida" (MCMV).

Especificamente quanto à aplicação de APO em conjuntos residenciais de custo controlado, Kowaltowski et al. (2013) explicam que os estudos utilizam instrumentos de APO com diferentes intuitos: visando investigar a apropriação dos espaços públicos e coletivos por parte da população, as condições de conforto e de desempenho das edificações (verificando como respondem a determinações normativas), ou mesmo se dedicam a aspectos mais relacionados a questões funcionais. No entanto, o instrumento de APO utilizado na experiência relatada foi constantemente analisado ereformulado para os objetivos da disciplina -como base inicial, utilizou-se a metodologia desenvolvida em pesquisas anteriores (RHEINGANTZ et al., 2009; VILLA, 2008; 2010) que enfoca aspectos funcionais, espaciais e comportamentais. Durante as diferentes experiências didáticas desenvolvidas, acrescentouse como escopo à metodologia inicial a investigação acerca de aspectos relativos à qualidade ambiental dos objetos estudados, permitindo também identificar o nível de consciência ecológica dos moradores. Portanto, a APO centrou-se em diferentes aspectos: funcionais, comportamentais e ambientais, conforme descrito a seguir. 


\section{A APLICAÇÃO DA APO NA DISCIPLINA API V}

Há variados instrumentos e técnicas de APO que podem ser aplicados, em função do tipo de avaliação que se pretende desenvolver e/ou das limitações existentes. No caso da experiência relatada, os procedimentos metodológicos elencados foram: levantamento de dados, registros fotográficos, entrevistas com moradores e aplicação de questionários.

Através da técnica do levantamento de dados, os pesquisadores coletam informações sobre o objeto investigado com base em visitas ao empreendimento e consultas com construtoras, órgãos públicos e escritórios responsáveis pelo projeto. Também são estabelecidos contatos iniciais com moradores e realizados registros fotográficos do edifício e de seu entorno complementando observações que não podem ser descritas somente com palavras, mas representadas com imagens.

Para auxiliar os alunos na elaboração de seus levantamentos, foram definidos os seguintes critérios de avaliação: (1) inserção urbana (vias de acesso, equipamentos e serviços do bairro); (2) inserção na quadra (relação entre elementos do conjunto - blocos, vias de circulação, áreas verdes e entorno); (3) restrições normativas (códigos de obras, zoneamentos); (4) densidades (gabaritos, número de habitantes/unidades $\times$ área); (5) acessos/circulações (horizontais e verticais); (6) estrutura (sistema adotado e características); (7) invólucro exterior (aberturas, vedações e cobertura); (8) instalações prediais e demais serviços; (9) tipologias (diversidade tipológica, tamanho e organização espacial das unidades); (10) flexibilidade (elementos de flexibilidade - existentes e possíveis); (11) conforto ambiental (orientação solar, ventilação e acústica); (12) impacto ambiental (estratégias de sustentabilidade - existentes e possíveis). Essa etapa teve como objetivo, portanto, compreender a relação entre unidade habitacional, espaços coletivos e inserção urbana. Além disso, visava examinar todos os elementos que compõem um edifício habitacional vertical - objeto que seria desenvolvido na etapa seguinte da disciplina API V.

Já a entrevista é uma técnica tradicional na pesquisa em ciências sociais adequada para a obtenção de informações sobre o que as pessoas sabem e sentem a respeito do conjunto habitacional em que vivem. Nesse caso, tal instrumento foi utilizado como complemento à técnica do questionário durante sua aplicação, incluindo, portanto, o registro de informações mais subjetivas ou não previstas nas questões inicialmente feitas aos moradores.

Um dos métodos mais utilizados em APO, o questionário, por sua vez, possibilita quantificar respostas dadas por um grupo heterogêneo de pessoas e que sejam de fácil consulta, diminuindo riscos de interpretações equivocadas. Esse instrumento ${ }^{2}$ foi elaborado pelos docentes conforme sua experiência de pesquisa e disponibilizado aos alunos, dividindo-se em cinco escalas de avaliação (Figura 1): dados pessoais dos entrevistados, avaliação do entorno de implantação, análise do conjunto habitacional e da escala do quarteirão, avaliação da unidade residencial (apartamento) e, por fim, hábitos dos moradores relacionados à eficiência energética e à sustentabilidade. No processo, foram aplicados 63 questionários, junto com moradores do Condomínio Embaúba em abril de 2015, tendo sido solicitado que os discentes realizassem, no mínimo, três questionários por dupla, em um total de quinze duplas. Antes da aplicação dessa técnica, foi feito contato com o síndico do condomínio, que tomou conhecimento do procedimento de avaliação, liberou o acesso dos alunos e fez contato prévio com os residentes para facilitar a APO. 
Figura 1: Categorias de análise do questionário

Fonte: Organizado pelos autores

Figura 2: Vista interna do Condomínio Embaúba

Fonte: Acervo da disciplina (2015)

\begin{tabular}{|c|}
\hline Termo de consentimento \\
\hline Características do entrevistado \\
\hline Entormo (bairro) \\
\hline Conjunto / quarteirão \\
\hline Unidade habitacional \\
\hline Eficiência energética e sustentabilidade \\
\hline
\end{tabular}

Quanto ao estudo de caso escolhido, o Condomínio Embaúba (Figura 2) é parte integrante do empreendimento Cidade Verde, localizado no Setor Oeste de Uberlândia (MG), tendo como principal acesso à Avenida Imbaúbas, conforme pode ser verificado no mapa de localização (Figura 3). A Secretaria Municipal de Habitação de Uberlândia desenvolveu o projeto de sete condomínios nesse empreendimento, que foram construídos em etapas, sendo que as unidades foram entregues aos moradores entre 2013 e 2014. O conjunto de condomínios totaliza 2.464 apartamentos, com população estimada de 8.400 pessoas, sendo destinado à Faixa 2 do programa "Minha Casa Minha Vida", ou seja, a famílias com faixa de renda mensal de até $\mathrm{R} \$ 3.275,00$ - grupo que seria trabalhado na fase de desenvolvimento dos projetos.
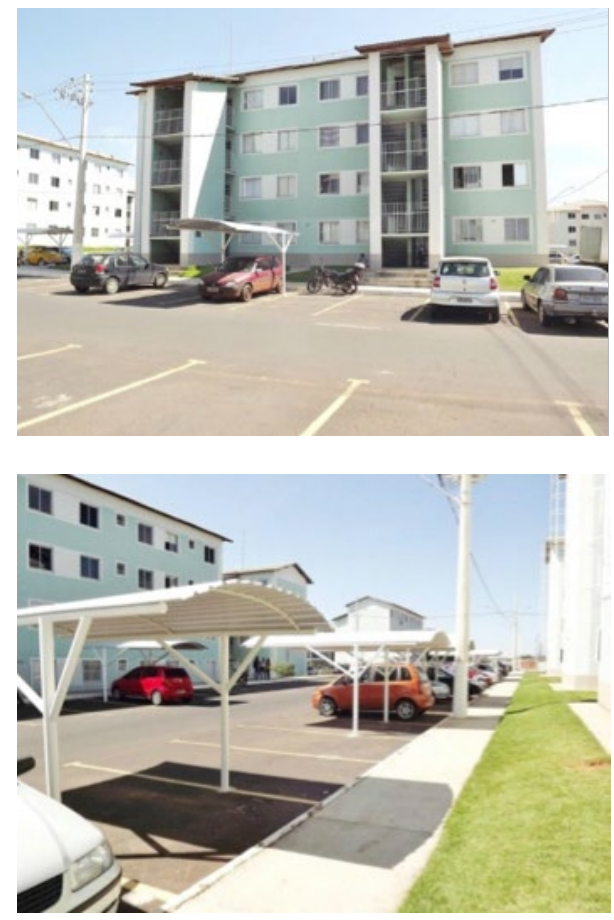

O Condomínio Embaúba conta com 400 unidades de dois quartos (Figura 4), seguindo o modelo tripartido em: área íntima (quartos e banheiro - indicada em lilás), social (sala - indicada em bege) e serviços (cozinha e área de serviço - indicada em verde). As unidades são distribuídas em 25 blocos, de 16 apartamentos cada, sendo quatro apartamentos por andar, sem elevador e pilotis, com acesso por duas escadas, além de uma vaga de garagem para cada unidade. A área útil dos apartamentos é de 37,05 $\mathrm{m}^{2}$. 


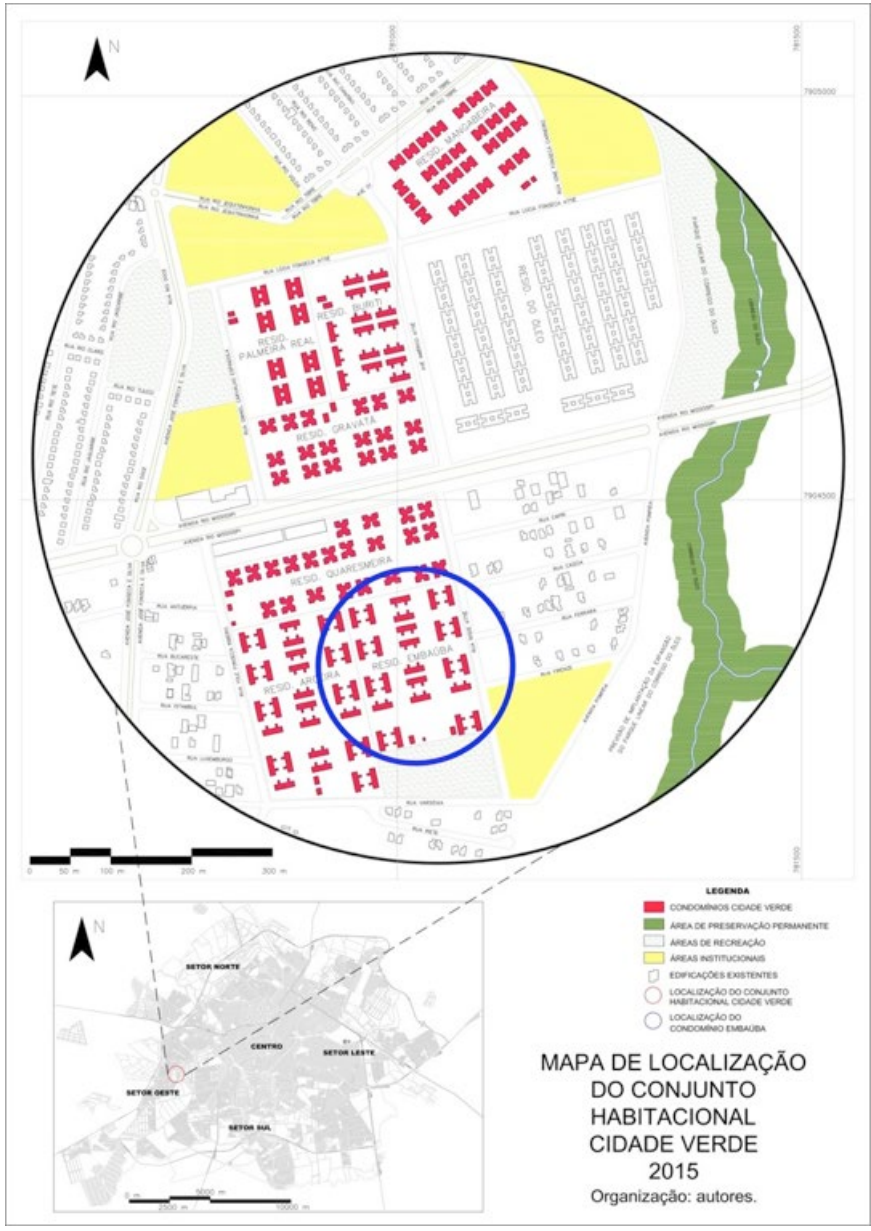

Figura 3: Mapa de localização do Condomínio Embaúba

Fonte: Prefeitura Municipal de Uberlândia, modificado pelos autores

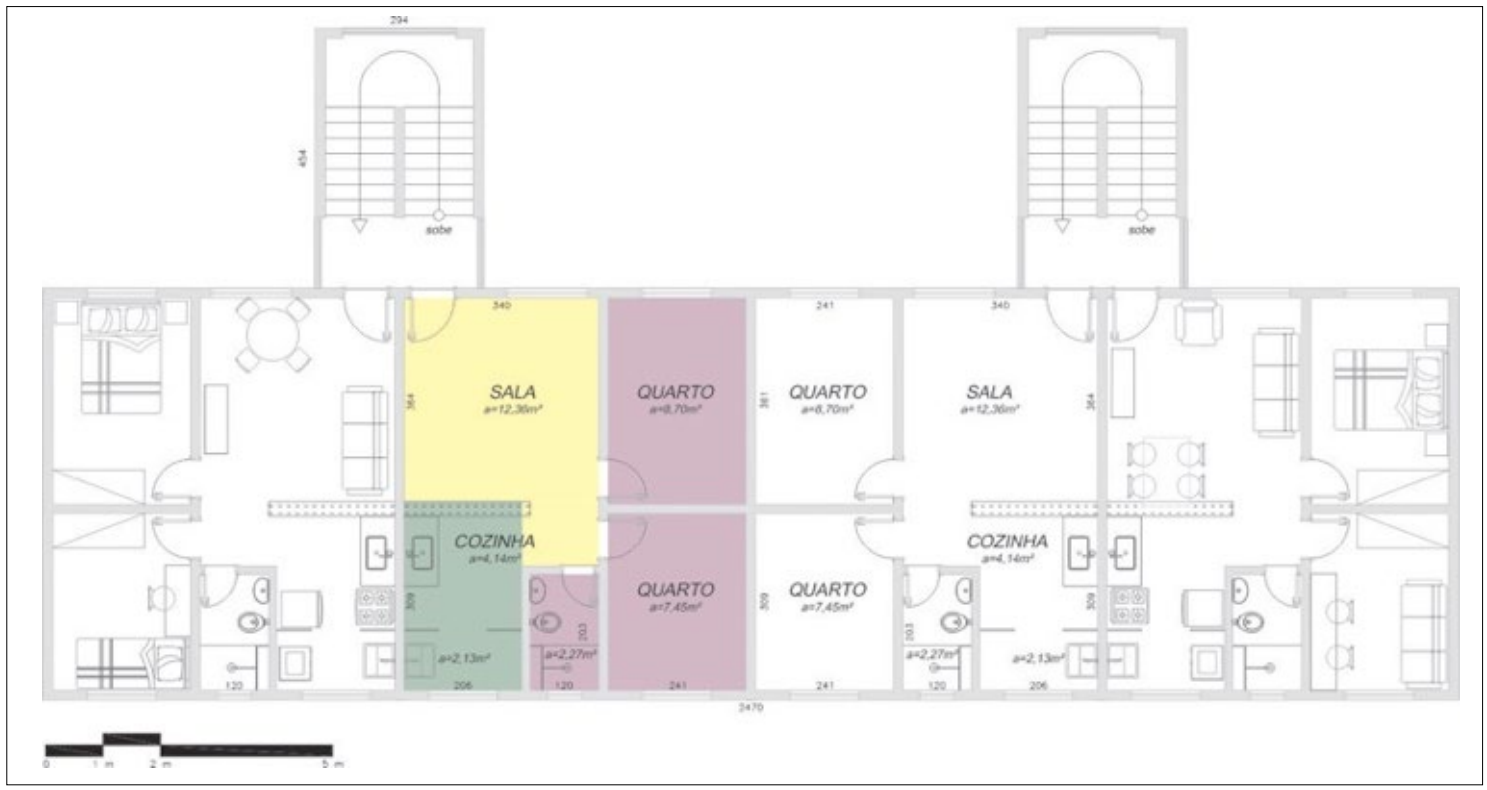

Após a aplicação dos instrumentos da APO, na aula de conclusão da atividade, os trabalhos foram apresentados em classe, fomentando-se a discussão entre os grupos sobre pontos comuns e divergentes verificados nas unidades habitacionais investigadas. Além da entrega do relatório completo de análise com a apresentação dos principais resultados por
Figura 4: Planta pavimento-tipo Condomínio Embaúba

Fonte: Prefeitura Municipal de Uberlândia, modificado pelos autores 
Figura 5: Elaboração de brainstorm com os resultados da APO

Fonte: Acervo dos autores (2015)

Figura 6: Apresentação de brainstorm com os resultados da APO

Fonte: Acervo dos autores (2015) grupo, os alunos, divididos em dois grandes grupos produziram, nesse momento, um brainstorm gráfico com uma síntese geral dos resultados mais significativos (Figuras 5 e 6). Os painéis criados foram afixados na sala de aula com o intuito de constantemente serem consultados e relembrados ao longo do desenvolvimento projetual.
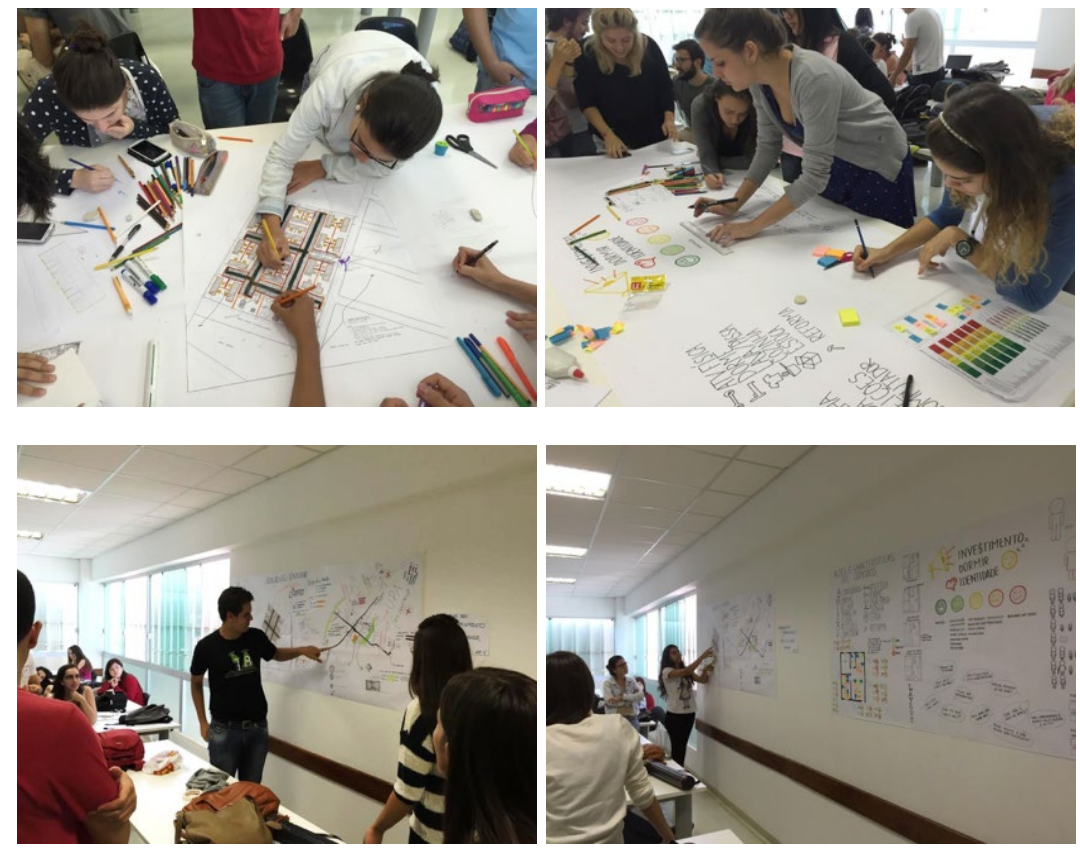

Já nessa atividade, tornou-se notável o aumento do conhecimento dos estudantes sobre o tema em questão, cujo senso crítico foi estimulado pela experiência da APO. A troca de conhecimentos entre os discentes foi fundamental, pois ampliou as possibilidades de leitura e interpretação dos problemas identificados, potencializando as futuras soluções propostas nos projetos. De acordo com os próprios alunos (conforme relatos em sala de aula), o processo de avaliação pós-ocupação foi essencial para 0 desenvolvimento das soluções projetuais, pois ofereceu um feedback dos moradores sobre os modelos habitacionais comumente ofertados no Brasil, contribuindo com a concepção de possíveis propostas de reestruturação do programa e das soluções de tipologias similares - tendo vista a qualidade (estética, funcional e ambiental) da habitação, bem como a consideração das necessidades dos usuários. Assim, na continuidade do semestre, trabalhou-se o desenvolvimento do projeto de um conjunto habitacional vertical, destinado a famílias de baixa renda, exercitando a capacidade propositiva dos alunos diante dos desafios identificados - como será apresentado a seguir.

\section{Os resultados da APO e o desenvolvimento das soluções projetuais na disciplina API V}

Para ilustrar a relação entre alguns resultados da APO e o desenvolvimento de soluções de projeto na disciplina API V, organizou-se tal análise seguindo as categorias de avaliação previstas no questionário aplicado. Assim, conforme as informações levantadas, quanto às características dos 63 respondentes: houve equilíbrio de gênero, mas relativa maioria de mulheres (55,93\%) e prevaleceu a idade adulta entre 20-40 anos (77,77\%). Em relação aos perfis familiares existentes, verificou-se que a maioria é de famílias nucleares (38,71\%), entretanto, são bastante representativos outros arranjos: Dinc (casal sem filhos) - 22,58\%, unifamiliar (pessoa só) - 17,74\%, e família monoparental (pai ou mãe + filhos) - 11,29\%. 


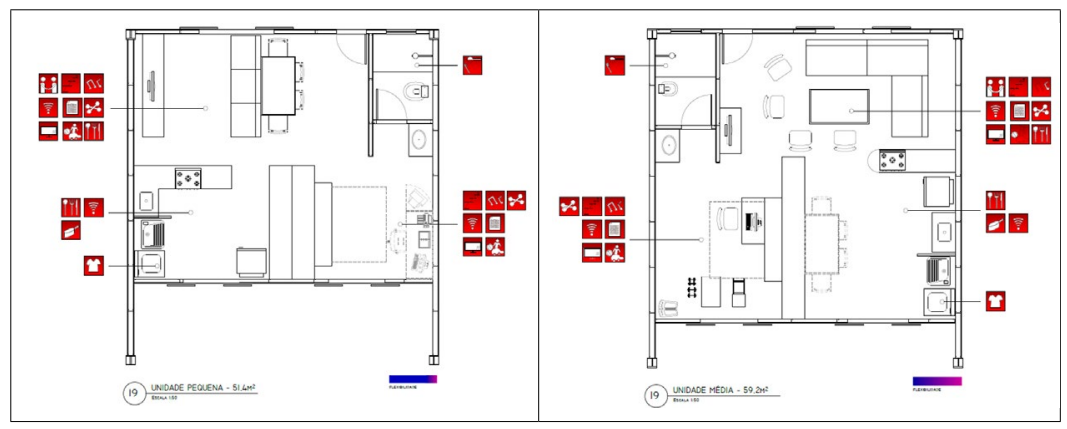

Nesse contexto, uma primeira influência dos resultados da APO foi a confirmação de discussões levantadas durante as aulas expositivas sobre a mudança nas composições das famílias brasileiras. A despeito disso, as unidades ofertadas pelo MCMV repetem um mesmo padrão de organização (sala, dois quartos, cozinha, banheiro e área de serviço), negligenciado necessidades espaciais heterogêneas. Por outro lado, considerando a existência desses diferentes perfis familiares, os alunos desenvolveram projetos de conjuntos habitacionais que contemplassem tipologias variadas (Figura 7) - abrigando, portanto, necessidades diversificadas (de pessoas vivendo sós a famílias com muitos membros). Com esse intuito, também propuseram elementos flexíveis (como painéis de correr e móveis escamoteáveis), de maneira a facilitar mudanças no layout das unidades, adequando-as a usos diurnos $\times$ noturnos. Outra proposta recorrente consistiu na tripartição do ambiente banheiro em cabines, objetivando potencializar seu uso por mais de um morador simultaneamente. Ademais, algumas propostas contemplaram ainda a possibilidade de expansão e de criação de novos cômodos (Figura 8).
Figura 7: Exemplo de variação de tipologias proposta pelos alunos, com indicação das possíveis ações nos espaços. Proposta de Lorena Spirandeli e Maryelen Lumi

Fonte: Acervo da disciplina (2015)

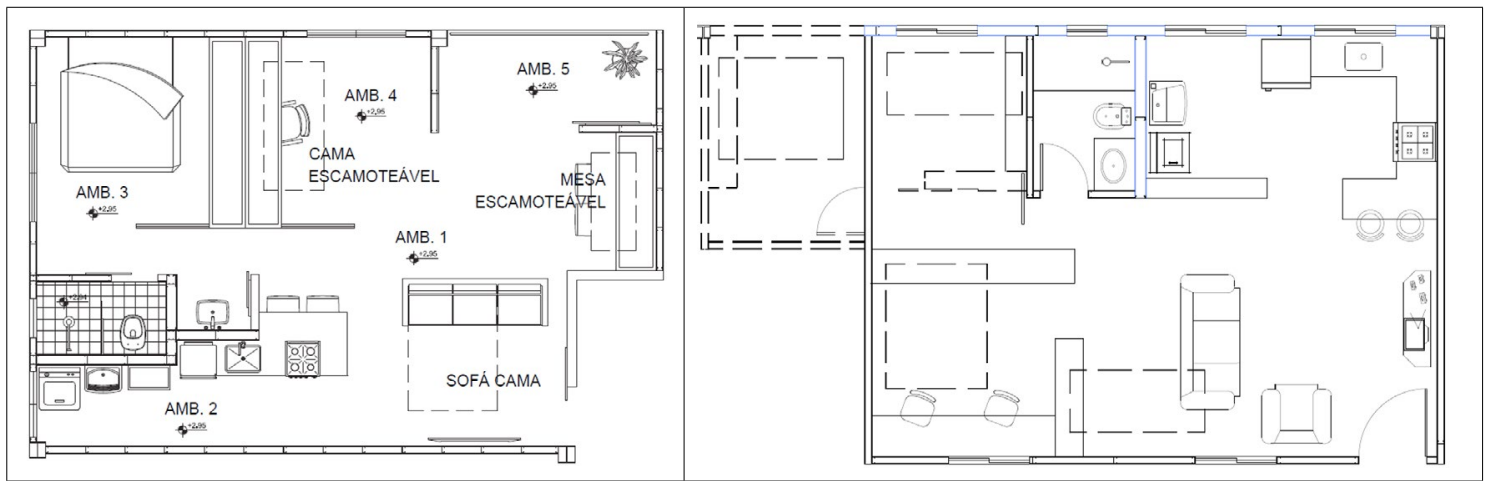

A segunda categoria de análise do questionário refere-se ao entorno. Quanto aos serviços existentes, verificou-se, na etapa de levantamento de dados, que o empreendimento é atendido por três linhas de ônibus, as quais se conectam à região central de Uberlândia. O bairro Jardim Europa, em que o conjunto se insere, não conta com equipamentos públicos de educação, somente uma escola infantil privada. Porém, em outros bairros do entorno, existem cinco escolas, que atendem ao ensino infantil, fundamental e médio - as quais, todavia, não conseguem contemplar a demanda de toda essa área da cidade. $O$ bairro também não possui equipamentos culturais ou de saúde, contudo, em bairros vizinhos há um posto de saúde e duas unidades de média complexidade - também incapazes de atender à demanda populacional existente. Por causa disso, quando consultados sobre a qualidade dos equipamentos públicos do entorno, verifica-se que a maioria dos entrevistados se encontra insatisfeita ou totalmente insatisfeita em relação aos aspectos levantados, exceto em relação ao transporte coletivo, que obteve melhor avaliação com os respondentes (Figura 9).
Figura 8: Uso diurno e noturno e possibilidade de expansão. Proposta de Beatriz Goulart e Túlio Zanatta; Ana Laura Barbosa e Thaís Castro Ávila, respectivamente

Fonte: Acervo da disciplina (2015) 
Figura 9: Qualidade dos equipamentos públicos.

Fonte: Organizado pelos autores.

Figura 10: Planta do térreo: no bloco à esquerda, estão as atividades comerciais e, à direita, unidades térreas com jardins privativos. Proposta de Beatriz Goulart e Túlio Zanatta

Fonte: Acervo da disciplina (2015).

Figura 11: Nível de satisfação sobre aspectos gerais do condomínio

Fonte: Organizado pelos autores

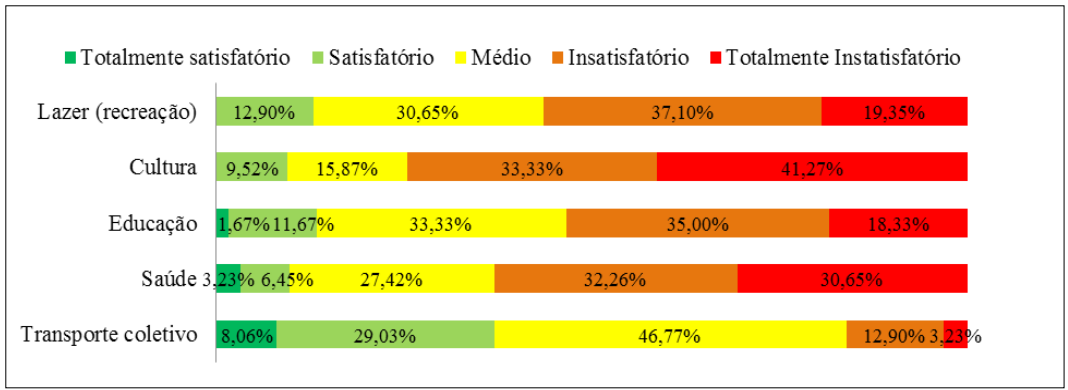

Levando em consideração esses dados, a definição da área de implantação das soluções de projeto de API V baseou-se na análise dos equipamentos públicos e serviços presentes, optando-se por desenvolver o exercício em uma região mais central de Uberlândia (MG). Dessa forma, torna-se possível otimizar a infraestrutura existente e, ao mesmo tempo, dinamizar uma região com uso predominantemente comercial da cidade, ao se propor um conjunto habitacional em suas imediações. Além disso, como resultado das entrevistas com moradores, que relataram sentir falta de alguns estabelecimentos comerciais e de serviços no próprio Condomínio Embaúba, os alunos propuseram usos mistos no térreo (Figura 10) de seus projetos, de maneira que tais atividades pudessem complementar as demais existentes no entorno e, simultaneamente, gerar renda para a manutenção dos conjuntos concebidos.
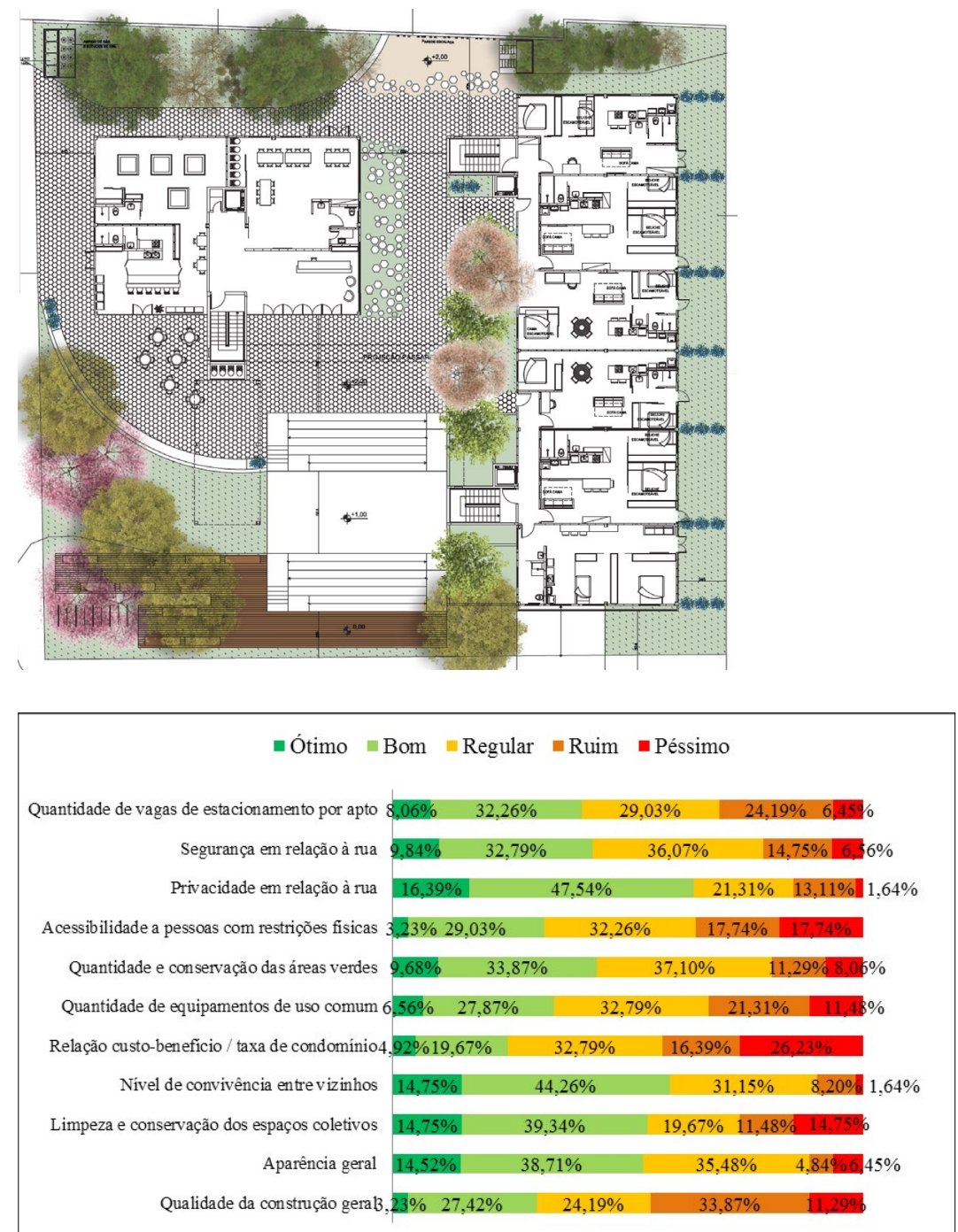
Afinal, no que se refere ao nível de satisfação em relação aos aspectos gerais do condomínio, a maioria dos itens foi classificada como ótimo ou bom, sendo bastante representativa, contudo, justamente a insatisfação dos residentes em relação ao custo-benefício e à taxa de condomínio bem como em relação à qualidade geral da construção e à acessibilidade a pessoas com restrições físicas (Figura 11). Em relação à qualidade de construção, os alunos desenvolveram pesquisas de materialidade, visando garantir a qualidade construtiva e estética de suas propostas, mesmo considerando a necessidade de controle de custos. Quanto à acessibilidade, houve preocupação na forma de acesso às unidades e aos espaços coletivos (com criação de rampas - Figura 10), bem como na concepção de tipologias acessíveis (estipulou-se que 20\% do total de unidades, no mínimo, deveriam ser acessíveis).

$\mathrm{Na}$ escala da unidade, diversas problemáticas foram identificadas - em função da redução dimensional dos espaços, da desconsideração da diversidade de perfis familiares (anteriormente analisada) e da sobreposição de usos não planejada. No entanto, é importante ressaltar que nem sempre esses problemas são objetivamente identificados pelos residentes. Por exemplo, muitos se consideram satisfeitos com o tamanho dos apartamentos, porém, quando indagados sobre a questão do mobiliário, mais de $60 \%$ dos entrevistados declararam que a quantidade de móveis que têm hoje é regular, ruim ou péssima, o que denota que o imóvel não atende às necessidades espaciais dos moradores. De forma semelhante, também o quesito "divisão dos cômodos" obteve avaliação ruim pelos usuários entrevistados (Figura 12).

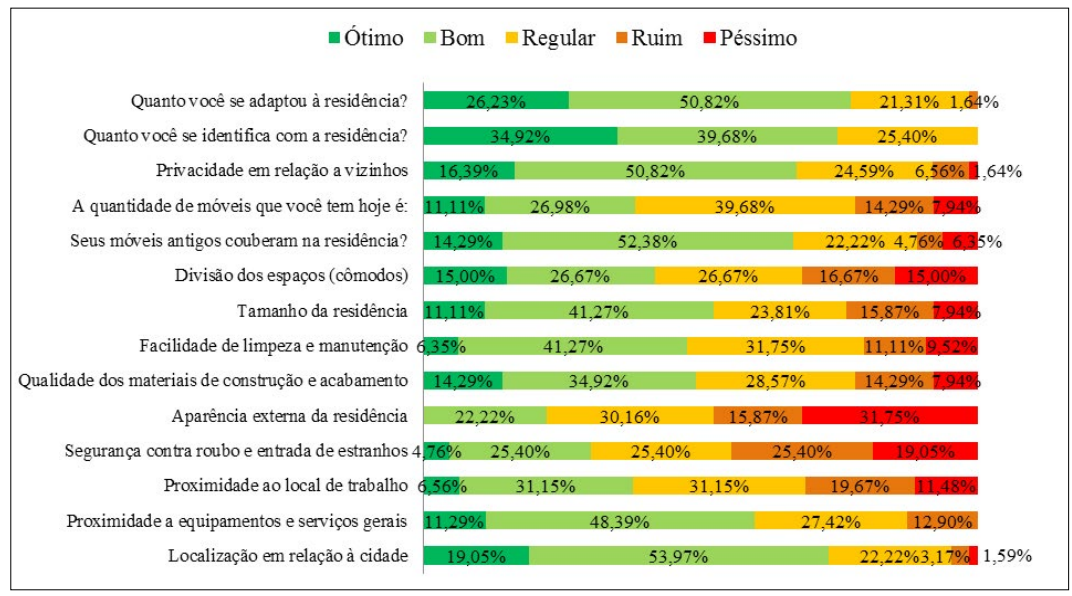

Outro aspecto que denota insatisfação diz respeito à realização de reformas nas unidades, visando adequá-las às necessidades das famílias. Em relação às reformas, $49,21 \%$ dos entrevistados declararam ter feito alguma modificação no apartamento - 44,44\% antes da mudança, principalmente para melhorar a aparência estética $(31,17 \%)$. Os principais cômodos que receberam alterações foram a cozinha $(30,23 \%)$ e o banheiro $(25,58 \%)$, em sua maioria para troca de acabamento $(32,31 \%)$ e colocação de armários (27,69\%). Porém, diferentes respondentes se queixaram da impossibilidade de realizar mudanças mais expressivas (envolvendo remoção de paredes para junção de cômodos, por exemplo), pois a estrutura do conjunto é de alvenaria autoportante. Portanto, depreende-se que, com o emprego de estrutura independente, provavelmente esses números seriam mais expressivos. Sendo assim, os discentes previram, em suas soluções, a adoção de sistemas estruturais independentes dos de vedação - os quais, por sua vez, também foram pensados de maneira a facilitar modificações dos espaços internos das unidades (por meio do emprego de componentes pré-fabricados leves, como painéis de OSB e cimentícios) - permitindo mais rápida adequação dos ambientes a mudanças.
Figura 12: Satisfação em relação aos aspectos da residência

Fonte: Organizado pelos autores. 
Figura 13: Sobreposição de usos

Fonte: Organizado pelos autores.

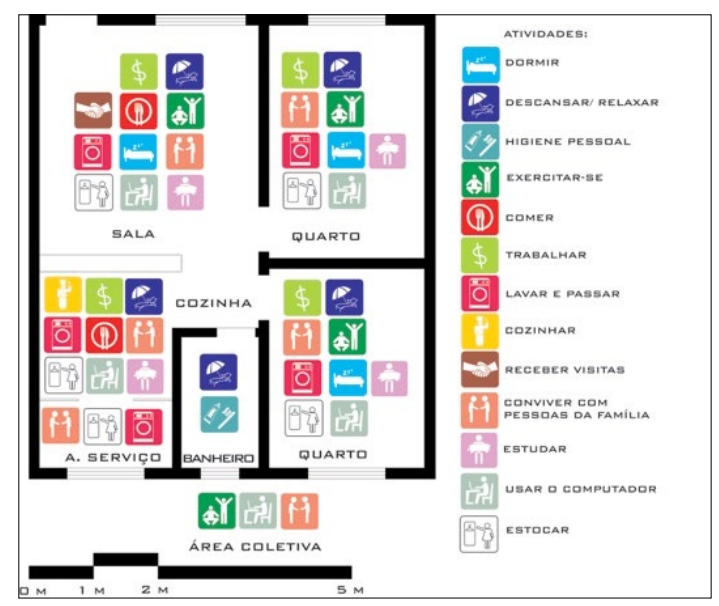

Figura 14: Exemplos de mobiliários flexíveis propostos pelos alunos. Proposta de Lorena Spirandeli e Maryelen Lumi

Fonte: Acervo da disciplina (2015)

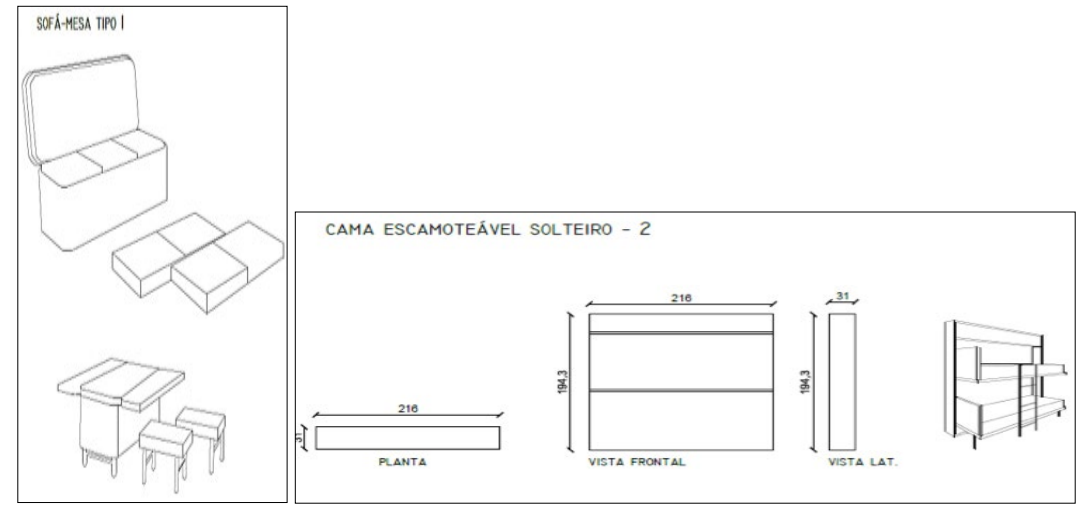

Observou-se, na etapa de levantamento de dados e nos questionários, que ocorre ainda sobreposição de usos de forma não planejada nas unidades (Figura 13). Atividades como o cuidado com as roupas, devido à pequena área de serviço, por exemplo, é realizada nos quartos e na sala. Para mitigar esses problemas, alguns alunos sugeriram a utilização de elementos flexíveis (como painéis de correr) que pudessem unir e dividir ambientes, atendendo a diferentes necessidades (Figuras 7 e 8), bem como projetaram soluções de mobiliário flexível (mesas extensíveis, camas escamoteáveis, entre outros) para otimizar o uso dos espaços (Figura 14). Outro problema relatado diz respeito à insuficiência da estocagem, por isso, em todos os atendimentos, os discentes foram estimulados a buscar soluções para 0 armazenamento enquanto elemento integrante dos projetos.

Por fim, a última categoria de análise visou avaliar a qualidade ambiental do conjunto. Nesse caso, observou-se a inexistência de estratégias voltadas a maior eficiência energética e sustentabilidade do edifício - embora, em sua fala, o síndico tivesse demonstrado interesse em implementar coleta seletiva e reuso de água no condomínio. Além disso, no estudo de caso, até mesmo as áreas verdes são residuais e não estimulam o convívio entre moradores. Por isso, em seus projetos, os alunos preocuparam-se tanto com o desenho dos espaços livres (Figura 10) - priorizando espaços coletivos em detrimento das vias de circulação para veículos, por exemplo (cuja proporção é bastante significativa no conjunto analisado) - quanto com a provisão de outros recursos voltados a reduzir os impactos ambientais de suas propostas - tais como aquecimento solar, reuso de águas cinzas, equipamentos economizadores de água, lixeiras seletivas, horta comunitárias, entre outros (Figura 15).

Ademais, preocuparam-se com a orientação solar dos blocos e das aberturas, projetando recursos de proteção para as fachadas mais desfavoráveis. Também buscaram soluções relativas à melhoria do 
desempenho acústico dos elementos de vedação - principal queixa dos moradores em relação ao conforto acústico dos espaços -, propondo o emprego de mantas e de isolantes entre as unidades - quando do detalhamento das mesmas.

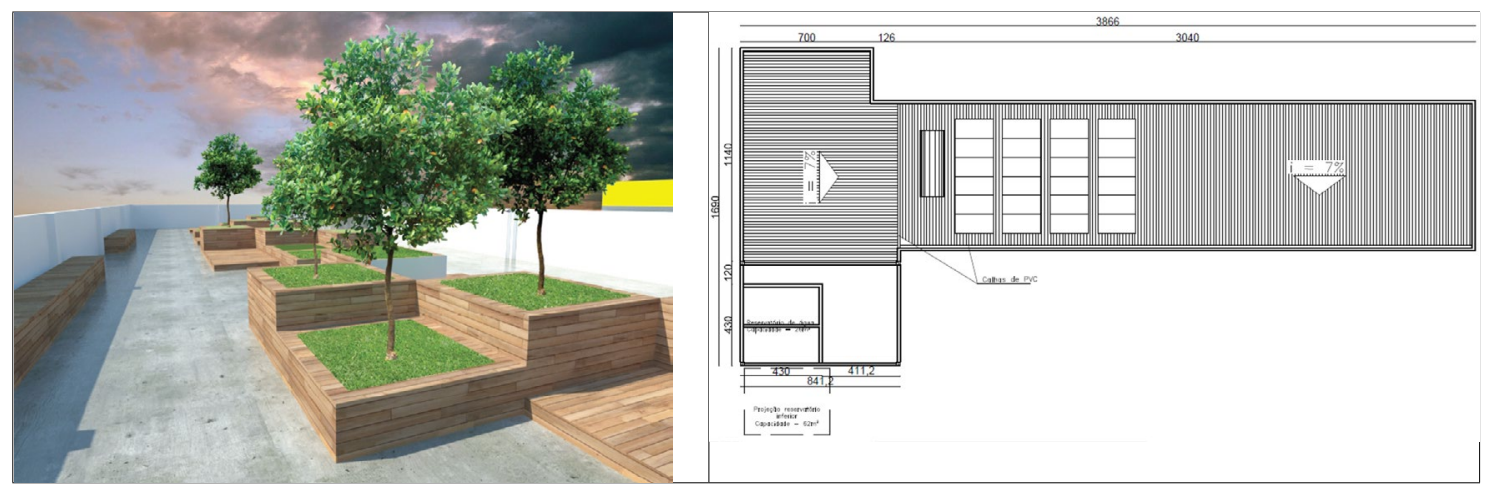

\section{CONSIDERAÇÕES FINAIS}

A experiência didática aqui apresentada pretende fomentar a discussão em meio acadêmico de possíveis interferências de avaliações sistemáticas, como a APO, sobre a concepção de novos projetos, especialmente no caso de estudantes, profissionais ainda em formação. Tomando como exemplo a experiência no curso de graduação da Universidade Federal de Uberlândia, de modo geral esse artigo pretendeu discutir a importância da APO como processo analítico crítico de ambientes habitacionais de interesse social, sobretudo tendo em vista a ampliação do arsenal de conhecimentos dos estudantes a respeito de suas características técnicas, funcionais, comportamentais e ambientais.

Durante os oito anos de experimentação na disciplina API V, na maioria dos casos observados houve expressivo aumento no repertório dos alunos, que repercutiu diretamente no novo produto projetado. Já em menor parte dos estudantes, a influência desse tipo de trabalho percebeu-se menos evidente ou direta. Para fins didáticos/acadêmicos, ressalta-se a necessidade de centrar as APO nos processos de concepção projetual, definição dos partidos e desenvolvimento da ideia até se chegar ao produto final em disciplina de graduação. Isso poderia acontecer com a imersão maior dos alunos na realidade estudada por meio da inserção nas disciplinas de ateliê de entrevistas, aplicação de questionários, medições, análises técnicas em estudos de caso similares ao projetado na disciplina - conforme vem sendo realizado na experiência relatada.

\section{REFERÊNCIAS}

ELALI, G. A. Avaliação pós-ocupação e responsabilidade social: uma relação a ser sempre (re)discutida. Gestão \& Tecnologia de Projetos, São Carlos, v. 5, n. 2, p. 3-17, nov. 2010.

ELALI, G. A.; VELOSO, M. Avaliação PósOcupação e processo de concepção projetual em arquitetura: uma relação a ser melhor compreendida. In: SEMINÁRIO INTERNACIONAL NUTAU, 6., 2006, São Paulo. Anais... São Paulo: FAU-USP, 2006. CD-ROM.

EVANS, G. W.; McCOy, J. M. When buildings don't work: the role of architecture in human health. Journal of Environmental Psychology, Amsterdam, n. 18, p. 85-94, 1998.

KOWALTOWSKI, D. C. C. K et al. (Orgs.). o processo de projeto em arquitetura: da teoria à tecnologia. São Paulo: Oficina de Textos; Fapesp, 2011

KOWALTOWSKI, D. C. C. K. et al. Métodos e instrumentos de avaliação de projetos destinados à habitação social. In: VILLA, S. B.; ORNSTEIN, S. W. (Orgs.). Qualidade ambiental na habitação: avaliação pós-ocupação. São Paulo: Oficina de Textos, 2013. p.149-184.
Figura 15: Vista de horta comunitária em cobertura e planta de cobertura com indicação de aquecimento solar. Proposta de Beatriz Goulart e Túlio Zanatta; Ana Laura Barbosa e Thaís Castro Ávila, respectivamente.

Fonte: Acervo da disciplina (2015). 
MAHFUZ, E. Ensaio sobre a razão compositiva. Viçosa: UFV, 1995

MALLORY-HILL, S.; PREISER, W.; WATSON, C. Enhancing building performance. New Jersey: Wiley-Blackwell, 2012.

ORNSTEIN. S. W. Avaliação pós-ocupação e estudos ambiente-comportamento: impacto das aplicações no ensino de projeto de arquitetura. In: DEL RIO, V.; DUARTE, C. R.; RHEINGANTZ, P. A. (Orgs.). Projeto do lugar: colaboração entre Psicologia, Arquitetura e Urbanismo. Rio de Janeiro: Contracapa; Rios Preciosos, 2002. p. 115-128.

ORNSTEIN, S; BRUNA, G; ROMÉRO, M. Ambiente construído e comportamento: a avaliação pós-ocupação e a qualidade ambiental. São Paulo: Studio Nobel; FAUUSP; Fupam, 1995.

PREISER, W. F. E.; RABINOWITZ, H. Z.; WHITE, E. T. Post-Occupancy Evaluation. Nova York: Van Nostrand Reinhold, 1988.

RHEINGANTZ, P. A. et al. Observando a qualidade do lugar: procedimentos para a avaliação pós-ocupação. Rio de Janeiro: Proarq; FAU; UFRJ, 2009.

SARAMAGO, R. C. P. et al. Morar coletivo em Habitação de Interesse Social: o caso do Conjunto Residencial São Jorge I. Cadernos Proarq, Rio de Janeiro, n. 24, p. 102-122, jul. 2015.

SOMMER, B; SOMMER, R. A practical guide to behavioral research: tools and techniques. Oxford: Oxford University Press, 1997.

VILLA, S. B. Morar em Apartamentos: a produção dos espaços privados e semiprivados nos apartamentos ofertados pelo mercado imobiliário no século XXI em
São Paulo e seus impactos na cidade de Ribeirão Preto. Critérios para Avaliação PósOcupação. 2008. 360 f. Tese (Doutorado em Tecnologia da Arquitetura) - Faculdade de Arquitetura e Urbanismo, Universidade de São Paulo, São Paulo, 2008.

A APO como elemento norteador de práticas de projeto de HIS: O caso do projeto [MORA]. In: CONGRESSO INTERNACIONAL HABITAÇÃO NO ESPAÇO LUSÓFONO, 1., Lisboa. Anais... Lisboa: LNEC, 2010. CD-ROM.

VILLA, S. B.; CAMPOS, C. R.; BRAGA, T. H. Avaliação pós-ocupação na disciplina de projeto de habitação social. In: Encontro Nacional sobre Ensino de Arquitetura e Urbanismo, 29., 2010, Porto Alegre. Anais... Porto Alegre: PUC-RS, 2010. CD-ROM.

VILLA, S. B.; ORNSTEIN, S. W. (Orgs.). Qualidade ambiental na habitação: avaliação pós-ocupação. São Paulo: Oficina de Textos, 2013

VILLA, S. B. et al. A ineficiência de um modelo de morar mínimo: análise pós-ocupacional em habitação de interesse social em Uberlândia-MG. OBSERVATORIUM: Revista Eletrônica de Geografia, Uberlândia, v. 5, n. 14, p.121-147, out. 2013

VILLA, S. B.; SARAMAGO, R. C. P; GARCIA, L. C. Avaliação pós-ocupação no programa Minha Casa Minha Vida: uma experiência metodológica. Uberlândia: UFU; PROEX, 2015.

VOORDT, T. J. M. Van Der; WEGEN, H. B. R. Van. Arquitetura sob o olhar do usuário: programa de necessidades, projeto e avaliação de edificações. São Paulo: Oficina de Textos, 2013.
Simone Barbosa Villa simonevilla@yahoo.com

Rita de Cássia Pereira Saramago saramagorita@gmail.com

Débora Cristina Araújo dca.arquiteta@gmail.com 